This item was submitted to Loughborough's Research Repository by the author.

Items in Figshare are protected by copyright, with all rights reserved, unless otherwise indicated.

\title{
Methodological considerations in using AcciMaps and the Risk Management Framework to analyse large-scale systemic failures
}

\section{PLEASE CITE THE PUBLISHED VERSION}

http://conferences.theiet.org/system-safety/programme/index.cfm

\section{PUBLISHER}

(C) Institution of Engineering and Technology (IET)

\section{VERSION}

AM (Accepted Manuscript)

\section{LICENCE}

CC BY-NC-ND 4.0

\section{REPOSITORY RECORD}

Waterson, Patrick, and Daniel P. Jenkins. 2019. "Methodological Considerations in Using Accimaps and the Risk Management Framework to Analyse Large-scale Systemic Failures". figshare.

https://hdl.handle.net/2134/7944. 
This item was submitted to Loughborough's Institutional Repository (https://dspace.lboro.ac.uk/) by the author and is made available under the following Creative Commons Licence conditions.

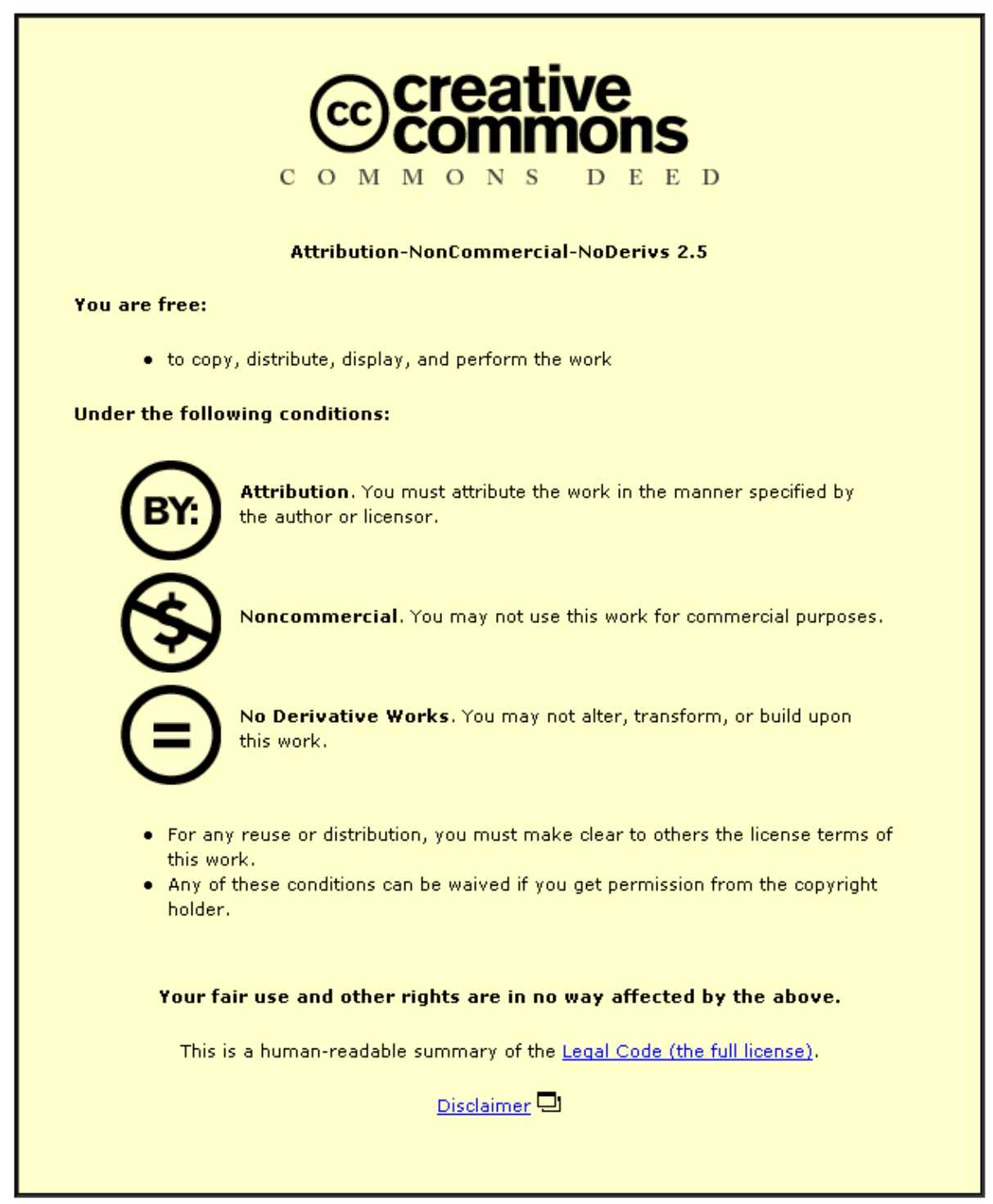

For the full text of this licence, please go to: http://creativecommons.org/licenses/by-nc-nd/2.5/ 


\title{
METHODOLOGICAL CONSIDERATIONS IN USING ACCIMAPS AND THE RISK MANAGEMENT FRAMEWORK TO ANALYSE LARGE-SCALE SYSTEMIC FAILURES
}

\author{
P.E. Waterson", D.P. Jenkins ${ }^{* *}$ \\ *Department of Ergonomics (Human Sciences), Loughborough University, UK, \\ ${ }^{* * *}$ Sociotechnic Solutions Ltd., St. Albans, Hertfordshire, UK., \\ Email: p.waterson@lboro.ac.uk, dan.jenkins@ sociotechnicsolutions.com
}

Keywords: Systems analysis; methods for accident and disaster investigation; AcciMaps; the Risk Management Framework; Human Factors.

\begin{abstract}
In this paper we describe our use of the AcciMap and Risk Management (ActorMap) framework (RMF) to analyse two recent accidents - the infection outbreaks which occurred at the Maidstone and Tunbridge Wells NHS Trust and the 2005 Stockwell Shooting incident. Previous work using AcciMaps and the RMF is described and reviewed in section 2 of the paper. We then describe the case studies followed by an account of our goals and the procedure used to carry out the accident analyses (section $3)$. The differences in our use of the methods are described in section 4 of the paper. Finally, we reflect on these differences in order to develop of a set of criteria which could be used to scope more detailed guidelines for the selection and use of the two methods.
\end{abstract}

\section{Introduction}

Complex sociotechnical systems are made up of a web of dynamic relationships and transactions. In many cases, systems drift into failure. The tendency to drift into failure and resultant disaster is on the increase as the combined influence of technological, environmental and social systems become more complex. A push for increased efficiency for example, or migration of behaviour (Rasmussen [17]), results in many decisions at multiple organisational levels. This push can occur over prolonged periods. As a result, in many systems, optimum efficiency lies on the boundary of safe operation. Furthermore, the problem is compounded as it is often difficult for operators to detect this drift (Perrow, [16]; Vaughan, [21]). Dekker [4] draws three parallels that unite this research: (1) accidents, and the drift that precedes them, are associated with normal people doing normal work in normal organizations; (2) organizations that involve safety-critical work are essentially trying to reconcile irreconcilable goals (staying safe and staying in business); (3) drifting into failure is incremental. Accidents do not happen suddenly, nor do monumentally bad decisions or huge steps away from the ruling norm preceding them. Within the context of the general public and the media they are commonly referred to as examples of 'large-scale system failure'.

Over the years, a large number of accident analysis techniques have been developed that recognise the importance of considering the environmental context and the role played by systemic failings at differing levels of the organisation. Some of these approaches are presented as frameworks or philosophies (e.g., Reason [18]) while others are presented as methods (e.g., STAMP - Leveson, [12]; the Risk Management Framework Rasmussen, [17]; AcciMaps - Svedung and Rasmussen, [19]). These techniques have been used to analyse a wide variety of domains and accident scenarios. The Risk Management Framework, for example, has been applied to the Walkerton e.Coli outbreak (Vicente and Christoffersen, [22]), as well as the UK BSE outbreak (Cassano-Piche et al., [3]).

The prevalence of different methods, and the numerous interpretations of each is most likely a result of the complexity bound within these domains, but it can also prove to be a challenge to those seeking some form of 'route map' of the territory as it applies to the analysis of systemic failure. Part of the problem is knowing where to start and judging the appropriateness of a specific technique for a particular domain. In general there is a lack of detailed guidance regarding when and how to use these different methods/techniques/frameworks.

In this paper we consider the use of two methods originally developed by Jens Rasmussen - the Risk Management (ActorMap) Framework (RMF) and AcciMaps. The paper came about as the result of the authors using these techniques independently in order to analyse two very different domains (Healthcare and Policing). Our specific objectives are: (1) To compare and contrast examples of recent applications of the RMF and AcciMap techniques for accident analysis; (2) To consider the differences in applications of the RMF and AcciMap techniques in terms of any assumptions underlying their use (e.g., types of data, methodology, differing goals driving use of the techniques); (3) To systematise common features and differences in use of the techniques in order to provide a set of criteria for selecting and using the methods for accident and disaster analysis. 


\section{AcciMaps and the Risk Management (ActorMap) Framework}

AcciMaps [19] is an accident analysis methodology that is used to represent graphically the causal factors involved in a particular accident or safety-compromising incident, occurring within complex socio-technical systems. The approach also captures the preconditions and actions behind that causal chain of events. AcciMaps are diagrams developed to support vertical integration across the control levels of a socio-technical system. The AcciMap approach differs from typical accident analysis approaches in that, rather than identifying and apportioning blame, it is used to identify and represent the causal flow of events and the planning, management and regulatory bodies that may have contributed to the scenario, with a view to improving system design and safety (Svedung and Rasmussen [19]). The AcciMap technique was developed to integrate the research of a number of disciplines, such as political science, decision theory, sociology, management studies and psychology. Rasmussen [17] also developed a more general modelling framework (the Risk Management (ActorMap) Framework) for understanding the dynamic interaction between these types of components within a large-scale sociotechnical system. The framework consists of two main components: a structural hierarchy describing the various actors; and, contextual factors influencing the activities of the actors. Table 1 summarises some of the studies which have made use of AcciMaps and the risk management framework.

\begin{tabular}{|c|c|c|}
\hline Source & Scope & $\begin{array}{l}\text { Characteristics } \\
\text { of Application }\end{array}$ \\
\hline $\begin{array}{c}\text { Rasmussen } \\
\text { [17]; Svedung } \\
\text { and Rasmussen } \\
{[19]}\end{array}$ & $\begin{array}{l}\text { RMF, description } \\
\text { of Conflict Map } \\
\text { and AcciMap } \\
\text { illustrated by } \\
\text { examples from } \\
\text { various accidents } \\
\text { (e.g., transportation } \\
\text { accidents, the } \\
\text { Zeebrugge } \\
\text { accident) }\end{array}$ & $\begin{array}{l}\text { Outline of RFM } \\
\text { with components } \\
\text { representing } \\
\text { Government, } \\
\text { regulators, } \\
\text { company, } \\
\text { management, } \\
\text { staff, work } \\
\text { context; } \\
\text { Detailed examples } \\
\text { of AcciMaps }\end{array}$ \\
\hline $\begin{array}{c}\text { Vicente and } \\
\text { Christoffersen } \\
\text { [22] }\end{array}$ & $\begin{array}{l}\text { RMF and AcciMap } \\
\text { - Walkerton E. coli } \\
\text { outbreak }\end{array}$ & $\begin{array}{l}\text { Mapping of } \\
\text { contributory } \\
\text { factors leading up } \\
\text { to the outbreak } \\
\text { using the RMF } \\
\text { and AcciMaps }\end{array}$ \\
\hline $\begin{array}{l}\text { Cassano-Piche } \\
\text { et al., [3] }\end{array}$ & $\begin{array}{l}\text { RMF and AcciMap } \\
\text { - UK BSE outbreak }\end{array}$ & $\begin{array}{l}\text { Mapping of } \\
\text { contributory } \\
\text { factors leading up } \\
\text { to the outbreak } \\
\text { using the RMF } \\
\text { and AcciMaps }\end{array}$ \\
\hline
\end{tabular}

Table 1: Summary of studies using AcciMaps and the Risk Management Framework

\begin{tabular}{|c|c|c|}
\hline Source & Scope & $\begin{array}{c}\text { Characteristics of } \\
\text { Application }\end{array}$ \\
\hline Hopkins [7] & $\begin{array}{c}\text { AcciMap - Esso } \\
\text { Gas Plant } \\
\text { (Longford) } \\
\text { Explosion }\end{array}$ & $\begin{array}{c}\text { Causal diagram of } \\
\text { contributory } \\
\text { factors leading up } \\
\text { to accident using } \\
\text { AcciMaps }\end{array}$ \\
\hline Johnson and de & RMF, AcciMap & Comparison \\
Almeida [10] & Brazilian space & between \\
& launch vehicle loss & Rasmussen and \\
& & Svedung's \\
& & $\begin{array}{c}\text { AcciMap [17] and } \\
\text { STAMP } \\
\end{array}$ \\
& & approaches [11]; \\
& & AcciMaps - 4 \\
& & steps: ActorMap; \\
AcciMap; Conflict & Map; \\
& & InfoFlowMap \\
\hline
\end{tabular}

Table 1 (cont.): Summary of studies using AcciMaps and the Risk Management Framework

As table 1 demonstrates, usage of the RMF and AcciMaps is subject to a good deal of variation, both in terms of scope and application of the methods. In some cases (e.g., [6]), one of the methods is used in isolation, however, the RMF and AcciMaps are more commonly used in combination. In the next section we describe in detail our application of the methods.

\section{Case studies}

\subsection{The $C$. difficile outbreaks within the Maidstone and Tunbridge Wells NHS Trust (Waterson, [23])}

During the period between April 2004 and September 2006 an estimated 90 people died at the Maidstone and Tunbridge Wells NHS Trust as a result of becoming infected with the Clostridium difficile ( $C$. diff.) bacteria (HC, $[5$, p.5]). The Healthcare Commission report identified a number of factors that contributed to the outbreaks that occurred with the Trust. These can be summarised in terms of five main themes: the role played by external organisations; management of the trust; clinical management on the hospital wards; the role played by the infection control team; and, equipment and hygiene factors. Figure 1 depicts some of these contributory factors using the Risk Management Framework.

At the very highest level of the system it is difficult to pinpoint exactly the role played by government-set targets as a discrete factor leading to the outbreaks. Targets placed many individuals, particularly those at trust board and management levels under a great deal of pressure. This pressure in itself may have led them to make poor decisions, and in some cases to prioritise bed occupancy rates at the expense of the risk of an infection outbreak. Previous research on the influence that targets have on management decision-making in health care tends to be equivocal. Within the 
trust it is likely that targets exerted considerable pressure on the system as a whole and this pressure filtered down various levels of the system. It is possible that the drive to comply with these targets increased the likelihood of an adverse event or set of events taking place at some stage within the trust.

Poor communication, confusion of responsibilities and accountabilities between and within the various regulatory bodies delayed the time in which they could react to the outbreaks. A separate report by the Healthcare Commission [6] examined the underlying causes of serious failures in NHS health care providers and identified large-scale organisational processes such as mergers and poor change management procedures as common factors.

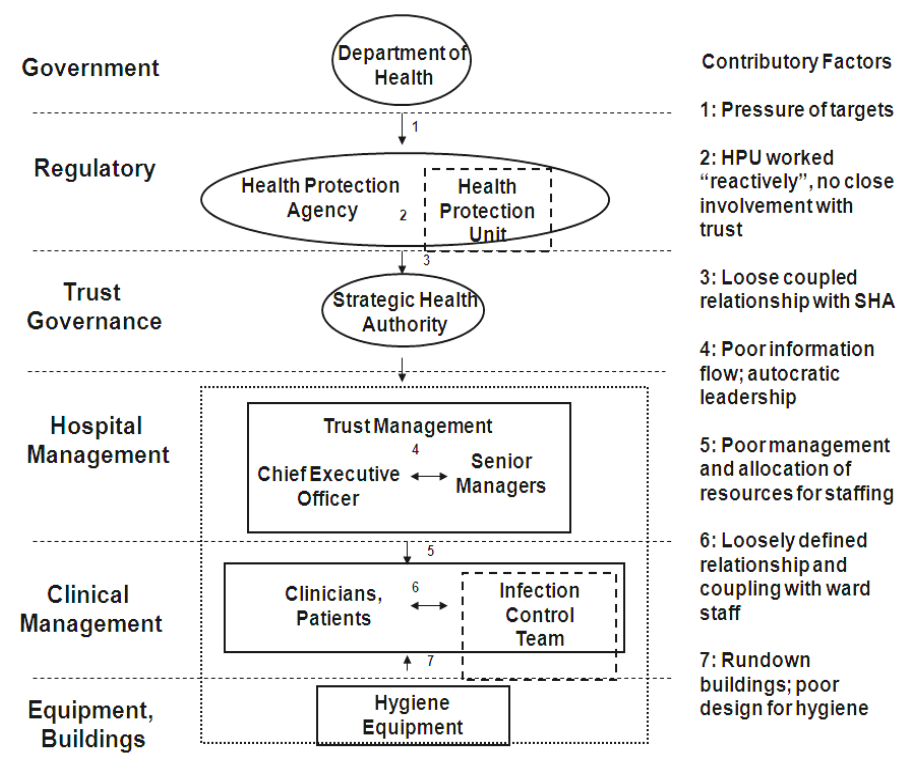

Figure 1: Risk Management (ActorMap) Framework applied to Infection Outbreaks within the Trust

Within the hospital the actions of senior managers were identified as significantly contributing to the failure to prevent and deal with the outbreaks. The link between management, human resource management (HRM) practices and work performance outcomes has been investigated in detail in the last few years. Wood and Wall [25] for example, reviewed the evidence that suggests there is a link between high-involvement HRM practices and employee productivity. High involvement HRM practices typically include empowering employees to make their own decisions and the presence of self-managed teams. The review showed that these types of practices in organisations do tend to increase levels of employee productivity. Similar effects have been shown between HRM practices and measurements of safety outcomes (e.g., number of adverse events). In general, there is strong evidence to suggest that aspects of management behaviour partially shape and determine the culture of safety within organisations (e.g., Zohar, [26]).

Aside from the way in which senior managers behaved at the trust, the question still remains as to why they ignored, or at least failed to realise the seriousness of the outbreaks and their consequences. Many of the managers interviewed in the original Healthcare Commission report reported that they were aware of how serious the situation had become within the trust, but were powerless to do anything about it. One possible explanation is what Vaughan [22] in her study of the Challenger shuttle disaster termed the "normalization of deviance", namely that managers over time began to accept and take for granted the level of infection risk within the Trust. Only after the level of risk built up to a point where it could not be controlled, did they begin to realise the gravity of the situation.

Understaffing and general lack of resources together played a part in the outbreaks. Staffing ratios and levels of staff morale almost certainly contributed to the problem of containing the spread of infection on the wards. In general, the research literature provides some evidence that lower levels of staffing increase the likelihood of infections occurring.

Finally, it might be conjectured that the behaviour of clinicians and other health care professionals within the trust shares similarities with those of senior managers and trust board managers. Many individuals at ward level were aware of the levels of poor hygiene and inadequate patient monitoring practices, but saw no way to improve the situation. Weick and Sutcliffe [24] analysed data from the Bristol Royal Infirmary Report and concluded that hospital staff became locked into particular lines of action or behaviour where they "search for confirmation that they are doing what they should be doing" (p. 73). These so-called "cultures of entrapment" inhibit an organisation's ability to break out of patterns of behaviour that, over time, can lead to adverse outcomes. In the case of the trust, they may provide some means with which to explain shared boundary spanning behaviours between levels within the hospital subsystem.

\subsection{The Stockwell shooting (Jenkins et al., [9])}

The Stockwell shooting incident, which took place in late July 2005 in South London (UK), followed on from a set of earlier terrorist bombings in London. At the time, a manhunt was on for the perpetrators of the attempted bombings which had taken placed on the previous day. A gym membership card had been found on one of the failed bombs and this connected Hussain Osman and the address ' 21 Scotia Road' to the attacks. As a result an operation was mounted at the address in order to apprehend Osman as he left the flat's communal entrance. At $0933 \mathrm{hrs}$ a man, allegedly bearing a resemblance to Osman, left the flat. Officers followed him on his 33-minute journey to Stockwell Tube Station. Two-minutes after he entered the station, members of the Metropolitan Police Service's (MPS) specialist firearms department (CO19) entered the station with order to 'stop' a suspected suicide-bomber. Surveillance officers directed them towards the subject. Moments later, two of the firearams officers approached the man and between them shot seven shots into his head from close range. The man was later identified Jean Charles de Menzies (JCdM), a completely innocent Brazilian national. 
Figure 2 shows part of a larger AcciMap which was developed using reports written by the Independent Police Complaints Commission [8] and the Metropolitan Police Authority [13] (a more detailed version is available in Jenkins et al., [9]). The events within the AcciMap are coded according to when they occurred (e.g., pre-operation, pre-JCdM leaving the flat). Figure 2 is made up of six levels; each of these levels involved various failures which ultimately led up to the shooting. The model highlights, amongst other things, that failings were present at all of the identified organisational levels. For example, at the lowest level, the observer 'Frank', positioned in a van outside the flat's communal door, failed to capture an image of JCdM. His decision to go to the toilet prevented him from switching on the video camera. Likewise, had Frank connected the camera to the van's power source or had there been a second observer, vital information could have been captured that may have led to the identification of JCdM.

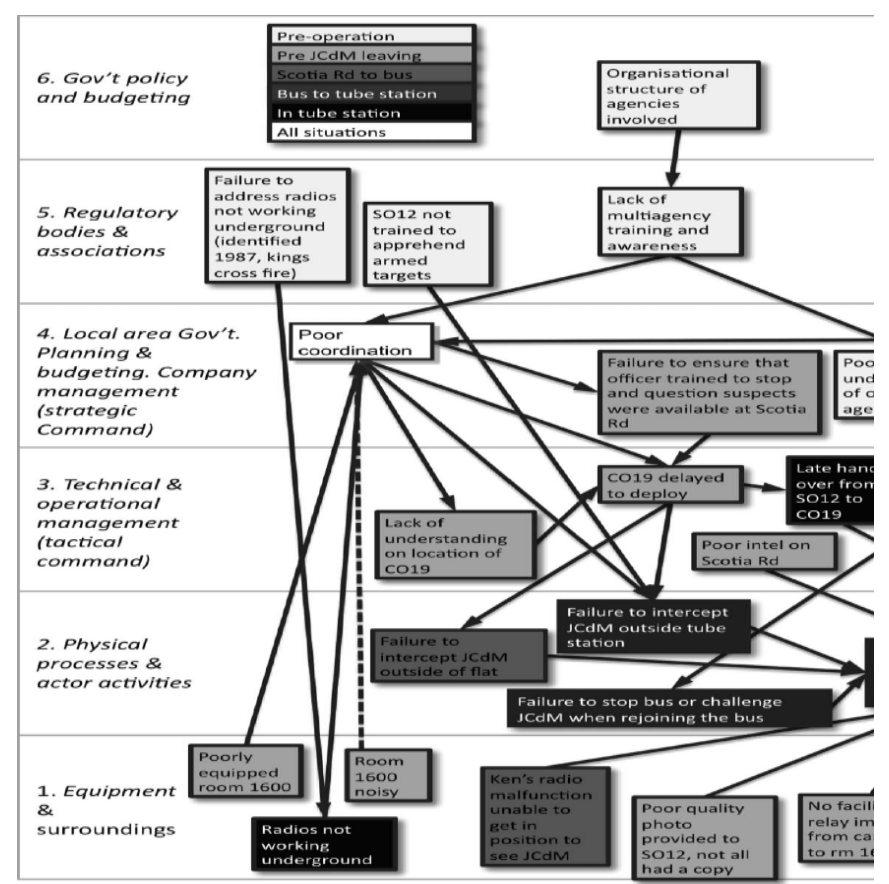

Figure 2: AcciMap applied to Stockwell shooting incident

A number of factors clearly predated the operation. In this case, at the higher organisational levels. Many of these failings relate to the ability of the system to process unambiguous information. For example, a failure to equip officers with radios capable of working underground (identified during the investigation into the 1987 Kings Cross Fire) meant that firearms officers had no contact with their superiors after entering the station. The organisation also appears to have lacked a well-trained lexicon relating to orders and rules of engagement. According to the IPPC report, the 'stop' command was not clear. A mismatch in understanding between the different levels of command was also evident. Information from officers on the ground was consolidated without considering the negative identifications. This undoubtedly affected the perception of those in the distributed command centre.

\section{Comparing our use of AcciMaps and the Risk Management Framework}

Our use of the RMF and AcciMaps showed some clear similarities and differences both in terms of the procedure which was used to carry out the analysis and the conclusions that were drawn regarding the causes of the accidents and incidents. Table 2 compares our use of the methods as they relate to our goals, intentions of use and procedure.

\begin{tabular}{|c|c|c|}
\hline & $\begin{array}{c}\text { AcciMaps } \\
\text { Jenkins et al. [9] }\end{array}$ & $\begin{array}{c}\text { Risk Management } \\
\text { (ActorMap) } \\
\text { Framework } \\
\text { Waterson [23] }\end{array}$ \\
\hline $\begin{array}{l}\text { Context } \\
\text { of use }\end{array}$ & $\begin{array}{l}\text { Command and } \\
\text { Control - Policing } \\
\text { Anti-Terrorism }\end{array}$ & $\begin{array}{l}\text { Healthcare - Hospital } \\
\text { Acquired Infections }\end{array}$ \\
\hline $\begin{array}{l}\text { Goals and } \\
\text { intentions } \\
\text { of use }\end{array}$ & $\begin{array}{l}\text { Modelling of the } \\
\text { events leading up to } \\
\text { the shooting (e.g., } \\
\text { capturing aspects of } \\
\text { decision-making, } \\
\text { communication, use } \\
\text { of equipment and } \\
\text { physical resources) }\end{array}$ & $\begin{array}{l}\text { Use of the systems } \\
\text { approach to analyse and } \\
\text { explain causes of the } \\
\text { outbreaks; to further } \\
\text { understand causal } \\
\text { linkages and } \\
\text { dependencies across } \\
\text { system levels }\end{array}$ \\
\hline Procedure & $\begin{array}{l}\text { 1. Description of } \\
\text { events leading up to } \\
\text { shooting } \\
\text { (i) Social network } \\
\text { diagramming of } \\
\text { actors and linkages } \\
\text { (ii) Chronology } \\
\text { (timeline) of events } \\
\text { (iii) Summary of } \\
\text { observation } \\
\text { statements } \\
\text { (iv) Diagram of } \\
\text { police office and } \\
\text { witness locations } \\
\text { 2. AcciMap analysis } \\
\text { Annotation of causal } \\
\text { factors according to } \\
\text { temporal aspects of } \\
\text { the incident }\end{array}$ & $\begin{array}{l}\text { 1. Systems description } \\
\text { (i) Timeline } \\
\text { (ii) Summary of } \\
\text { contributory factors in } \\
\text { HC (2007): } \\
\text { 2. Systems analysis } \\
\text { Use of the Risk } \\
\text { Management (ActorMap) } \\
\text { framework focusing on: } \\
\text { (i) Cross-level } \\
\text { relationships related to } \\
\text { previous findings in the } \\
\text { literature } \\
\text { (ii) Whole system } \\
\text { relationships related to } \\
\text { previous findings in the } \\
\text { literature }\end{array}$ \\
\hline
\end{tabular}

Table 2: Comparison of use of the RMF and AcciMap in the case studies

The clearest differences in the use of the methods relates to the goals and intentions behind the analysis of the two accidents. In the case of the Stockwell shooting, one of the goals was to capture the dynamic nature of communication and decisionmaking as it took place over a short period of time. Much of the data which formed the AcciMap was directly taken from the various reports written about Stockwell. This is especially the case at lower levels of the AcciMap (i.e., levels 1-3). By contrast, the Infection case study was motivated by the need to explore a 
set of more loosely defined factors that could be linked together to explain the recurrence of the outbreaks. Part of the intention was to go beyond some the dominant explanations of infection outbreaks (e.g., compliance to hygiene protocols) and seek explanations from the findings relating to similar organisational issues within accident research. Accordingly, the infection case study tended to identify explanations at higher levels of the RMF. Data covering the outbreaks was less detailed as compared to Stockwell and partly motivated the need to see explanations across levels of analysis. The timescale for the outbreaks was also much longer ( 2 years), as compared to the minute-by-minute unfolding of activities in the Stockwell shooting.

Aspects of our goals and intentions of use with the methods, as well as the nature of data and the domain in question shaped the procedure used in the accident analysis. In many ways, our use of the methods appeared to be guided by implicit assumptions about their scope and suitability of their use for the two case studies. In the final section of the paper we focus on a set of criteria which could be used to judge the suitability, as well as scoping the procedural aspects, of the RMF and AcciMaps methods.

\section{Discussion}

In using the RMF and AcciMaps we were struck by the large range of alternatives and options for configuring and reconfiguring the original components set out by Rasmussen in his original description of the RMF and AcciMaps methods. This flexibility led us to attempt to articulate a set of criteria which could be help potential users to judge the suitability of one method, or type of procedure, against another. This type of 'front end' guidance contrasts with the type of support provide by Branford et al. [2] which attempts to lay out a set of guidelines for building AcciMaps.

An additional difference is that we focus not only the procedural aspects of systems analysis, but also on some of the conceptual choices and options which may be open to the analyst. Other methodologies for the analysis of complex work systems have benefited from the development of similar guidelines and considerations (e.g., Cognitive Work Analysis - Naikar et al., [14]). A final consideration is that the criteria are not intended to be prescriptive; rather, the intention is to support the flexible and sometimes exploratory nature of the two methods.

\subsection{Establishing the purpose of the analysis}

The most important step before beginning the analysis is to establish its purpose and overall goals. With the infection outbreak case study the intention was primarily to explore the interplay between the various causal factors leading up to the outbreaks. These factors unfolded over longer timescales as compared to Stockwell and what Turner called the incubation period' [20] for the outbreaks was much longer. These types of considerations shaped the choice of the method in this case (RMF), as compared to Stockwell where the dynamics of the shooting required a more distributed, 'time-stamped' representation within the AcciMap.

\subsection{Consideration of the role of causality, intentionality and the nature of system error in the analysis}

The distributed nature of error alongside the differences in timescale within the two case studies also shaped the outcomes from the analysis. The RMF was also chosen because it facilitated consideration of cross-level causal connections and linkages between macro and micro elements of the overall system. Error in this context was difficult to pin down to specific individuals, instead it manifested itself as a set of shared attitudes which infiltrated the culture of the hospital and blocked organisational learning. Organisational error in this form was easier to conceptually explore using the RMF. With Stockwell by contrast, the AcciMap format was more suited to building a 'causal map' bringing together processes of decision-making and communication.

\subsection{Domain specific considerations}

The nature of the two domains and the structural properties of the systems and sub-systems within the case studies also played a role in shaping the choice of method. The infection outbreak involved a widely distributed and diverse set of organisations and actors. Coupling between the various actors within the overall system was often very loose. Within Stockwell the degree of coupling was similarly loose at upper levels of the AcciMap, but tighter within the lower levels. Consideration of issues of coupling between levels, as well as the communication requirements of actors in the system, also shaped the choice of the methods.

\subsection{Data and information inputs to the analysis}

Our use of the two methods showed some procedural similarities. Both cases started out by carrying out what might be called 'domain analysis', that is, developing an understanding of the domain independent of the accident or disaster in question. This may involve reading accounts of similar accidents (e.g., other infection outbreaks, the report on the Kings Cross fire). Documentary inputs into the analysis can determine the nature of the method used. The RMF for example, was used for the Infection case study partly because information was unavailable regarding the specific actions of individuals (e.g., health care managers). Similar information on decision-making, communication was available for the Stockwell and was therefore more appropriate for analysis using AcciMaps.

\subsection{Constructing RMF and AcciMap representations}

The most extensive set of guidelines for using and constructing AcciMaps are available in Branford et al. [2]. These cover a set of prompts and questions to be used at levels within the AcciMap. These types of support for analysis can be very useful; however, there is also an additional need to build some form of wider options for choices which may be possible at each level. This is especially the case where the specific prompts or questions to ask at each level are dependent on characteristics of the domain or the nature of error in the system. Our experience of using the methods is that these guidelines could be extended to 
cover options for potential modifications to the methods (e.g., the use of multi-level theory, decision-ladders).

\subsection{Reviewing and validating the analysis}

The issue of the reliability and validity of the AcciMaps and RMF methods has been raised by a number of authors (e.g., [10, 15]). Our experience is that in some cases, for example where the primary motivation for using the method is exploratory (e.g., in infection outbreaks case study), extensive validation may not be necessary. Branford [1] found that these are difficult with AcciMaps and that there is a need to acknowledge the subjective nature of analysis. Her findings suggested that there is a need to capture the underlying process and rationale during AcciMap judgments and decisions.

\section{Future work}

The criteria outlined in section 5 need further refinement and development. We hope to use some of the other examples of use of the RMF and AcciMaps (section 4) as a basis with which to develop more detailed and extensive guidance regarding the possibilities for using, tailoring and configuring components of the methods. Similarly, future work needs to be conducted on the provision of support in order to improve the reliability and validity of the two methods.

\section{References}

[1] K. Branford. "An Investigation into the Reliability and Valdity of the AcciMap Approach". Unpublished PhD thesis, Australia National University. (2007)

[2] K. Branford, N. Naikar and A. Hopkins, "Guidelines for AcciMap analysis". In A. Hopkins (Ed.), Learning from High Reliability Organisations. Sydney: CCH. (2009)

[3] A. Cassano-Piche, K.J. Vicente and G.A. Jamieson. "A test of Rasmussen's risk management framework in the food safety domain: BSE in the UK". Theoretical Issues in Ergonomics Science, 10, 283-304. (2009)

[4] S.W.A. Dekker. "Why we need new accident models". Lund University School of Aviation Technical Report 200502. (2005)

[5] Healthcare Commission. "Investigation into outbreaks of Clostridium difficile at Maidstone and Tunbridge Wells NHS

Trust". (http://www.healthcarecommission.org.uk/_db/_documents/ Maidstone_and_Tunbridge_Wells_investigation_report_Oct _2007.pdf (2008).

[6] Healthcare Commission "Learning from Investigations" (http://www.healthcarecommission.org.uk/_db/_documents/ Learning_from_investigations.pdf (2008).

[7] A. Hopkins, "Lessons From Longford", Sydney: $\mathrm{CCH}$ Books, (2000)

[8] Independent police complaints commission (IPCC).
Stockwell One: Investigation into the shooting of Jean Charles de Menezes at Stockwell underground station on 22 July 2005. (2007)

[9] D.P. Jenkins, P.M. Salmon, N.A. Stanton. and G.H. Walker, G.H. "A systemic approach to accident analysis: A case study of the Stockwell shooting". Ergonomics, 53, 1-17. (2010)

[10] C.W. Johnson I.M. de Almeida, "An investigation of the loss of the Brazilian space programme's launch vehicle VLS-1 V03", Safety Science, 46, 38-53 (2008)

[11] N.G. Leveson, "Applying systems thinking to analyze and learn from events", Safety Science, in press, (2010).

[12] N.G. Leveson. "A new accident model". Safety Science, 42, 237-270. (2004)

[13] Metropolitan Police Authority (MPA). MPA Stockwell Scrutiny http://www.mpa.gov.uk/downloads/reports/ stockwellscrutiny.pdf accessed 23/01/2009) (2008)

[14] N. Naikar, A. Moylan and B. Pearce. "Analysing activity in complex systems with cognitive work analysis: Concepts, guidelines, and case study for control task analysis". Theoretical Issues in Ergonomics Science.,7, 371-394. (2006).

[15] D. O'Hare. 'The 'Wheel of Misfortune': a taxonomic approach to human factors in accident investigation and analysis in aviation and other complex systems", Ergonomics, 43, 2001-2019, (2000).

[16] C. Perrow. "Normal Accidents". Princeton: Princeton University Press. (1984),

[17] J. Rasmussen. "Risk management in a dynamic society: a modeling problem". Safety Science, 27, 183-213. (1997),

[18] J. Reason. "Human Error". Cambridge: Cambridge University Press. (1990)

[19] I. Svedung and J. Rasmussen. "Proactive Risk Management in a Dynamic Society". Karlstad: Swedish Rescue Services Agency. (2000)

[20] B. Turner. "Man-Made Disasters". London: Wykeham Publications. (1978)

[21] D. Vaughan. "The Challenger Launch Decision: Risky Technology, Culture and Deviance at NASA" Chicago: Chicago University Press. (1996)

[22] K.J. Vicente and K. Christoffersen. The Walkerton E. Coli outbreak: a test of Rasmussen's framework for risk management in a dynamic society. Theoretical Issues in Ergonomics Science, 7, 2, 93-112. (2006)

[23] P.E. Waterson "A systems ergonomics analysis of the Maidstone and Tunbridge Wells infection outbreaks". Ergonomics, 52, 1196-1205. (2009)

[24] K.E. Weick and K.M. Sutcliffe. "Hospitals as cultures of reenactment: a re-analysis of the Bristol Royal Infirmary". California Management Review, 45, 2, 73-84. (2003)

[25] S. Wood and T.D. Wall. "Human resource management and business performance." In P.B. Warr (Ed.), Psychology at Work $\left(5^{\text {th }}\right.$ edition). Harmondsworth: Penguin Books. (2002)

[26] D. Zohar. "A group-level model of safety climate: Testing the effect of group climate on microaccidents in manufacturing jobs". Journal of Applied Psychology, 85, 587-96. (2000) 